\title{
Involvement of Norepinephrine in the Control of Activity and Attentive Processes in Animal Models of Attention Deficit Hyperactivity Disorder
}

\author{
D. Viggiano, L.A. Ruocco, S. Arcieri and A.G. Sadile \\ Laboratory of Neurophysiology, Behaviour \& Neural Network, Department of \\ Experimental Medicine, II Univ. Naples, Naples, Italy
}

SUMMARY

Functional and morphological studies in children affected by Attention Deficit Hyperactivity Disorder (ADHD) suggest a prefrontal cortex (PFc) dysfunction. This cortical region is regulated by subcortical systems including noradrenergic (NEergic), dopaminergic (DAergic), cholinergic, serotonergic, and histaminergic pathways. A wealth of data in humans and in animal models demonstrates altered dopamine (DA) regulation. Drugs that modulate norepinephrine (NE) transmission are also effective in ADHD patients, thus leading to the hypothesis of a NEergic disorder. This review covers the regulation of $\mathrm{PFc}$ functions by $\mathrm{NE}$ and the interaction between the NE and DA systems, as suggested by pharmacological, electrophysiological, morphological, and gene knock out (KO) studies. A negative feedback between NE and DA neurons emerges from $\mathrm{KO}$ studies because $\mathrm{KO}$ mice showing increased (NE transporter (NET) KO) or decreased (DBH and VMAT2 KO) NE levels are respectively associated with lower and higher DA levels. Locomotor activity can be generally predicted by the DA level, whereas sensitivity to amphetamines is by NE/DA balance.

Reprint requests to: A.G. Sadile, Lab. Neurophysiol., Behav. \& Neural Networks, Dept. Experimental Medicine II University of Naples, Costantinopoli 16, 80138, Naples, Italy; e-mail: adolfo.sadile@unina2.it
Some animal models of ADHD, such as spontaneously hypertensive rats (SHR), show alterations in the PFc and in the DA system. Evidence about a correlation between the NE system and hyper-locomotion activity in such animals has not yet been clarified. Therefore, this review also includes recent evidence on the behavioral effects of two NET blockers, reboxetine and atomoxetine, in two animal models of ADHD: SHR and Naples High Excitability rats. As these drugs modulate the DA level in the PFc, certain effects are likely to be due to a rebalanced DA system. We discuss the significance of the results for theories of ADHD and make suggestions for future experimentation.

\section{KEYWORDS}

ADHD, norepinephrine system, dopamine system, norepinephrine transporter inhibitors, prefrontal cortex, motor activity, attention, behavior, review

\section{INTRODUCTION}

The grayish-blue colored small pigmented region of the fourth ventricle floor, the locus coeruleus (LC), includes a cluster of about 1600 neurons per nucleus in rats, several thousand in monkeys, and 10,000 to 15,000 in humans (Foote et al., 1983; for review see Berridge \& Waterhouse, 
2003). These neurons contain norepinephrine (NE), as shown by Dahlstrom and Fuxe in 1964 (1964), and are the origin of widespread nerve terminals in the mammalian brain and spinal cord (Loughlin et al., 1982; Fallon \& Loughlin, 1982). Norepinephrine neurons give rise to two major bundles, the dorsal and ventral one. The former (dorsal tegmental bundle) originates from LC neurons and terminates in many regions of the forebrain, cerebellum, and spinal cord (Cerbone \& Sadile, 1994). The latter or central tegmental tract originates from diffuse NE cell groups in the pons and medulla and terminates in the hypothalamus and spinal cord (Mason, 1981).

Norepinephrine LC cells fire monotonically $(2-4 \mathrm{~Hz}$ in the tonic mode) in relation to stages of sleep and waking, with the highest rates occurring during wakefulness (Robbins, 1997). Moreover, LC cells respond to novel or noxious stimuli, conditioned stimuli, and appetitive events (Robbins, 1997; Bouret \& Sara, 2002). They play, in fact, regulatory effects on attention and arousal, fear and anxiety, information storage and locomotor activity (for review see Mason, 1981; Cerbone \& Sadile, 1994; Sadile, 1996; Robbins, 1997).

Several drugs interfere with the NE system. The psychostimulant amphetamine and the dopamine (DA) transporter blocker, methylphenidate, inhibit LC firing (Lacroix \& Ferron, 1988). Interestingly, both drugs are largely used in the treatment of a disorder characterized by hyperactivity and inattention, known as attention deficit hyperactivity disorder (ADHD). As a consequence, the possibility that ADHD represents a NEergic disorder has been recently discussed (Biederman \& Spencer, 1999).

Attention deficit hyperactivity disorder is a neurodevelopmental problem diagnosed in 1 to 3 percent of children (Castellanos\& Tannock, 2002; Sergeant et al., 2003). The main features are "a persistent pattern of inattention and/or hyperactivity/impulsivity that is more frequently displayed and more severe than in individuals at a comparable level of development" (American
Psychiatric Association (APA), 1994). The disorder can occur before the $7^{\text {th }}$ year of age and in different environments. Different variants have been identified: hyperactive-impulsive, inattentive, and combined (APA, 2004).

The contributions of NE and DA neurotransmissions to the motor and cognitive symptoms of ADHD have been investigated in rodent and primate models and in humans as well (Castellanos et al., 1996). Dopamine and NE interact at their nuclei of origin and at shared target sites, such as the prefrontal cortex (PFc) (Berridge \& Waterhouse, 2003), wherein the control of DA and NE is very complex. Interestingly, the PFc has shown typical functional alterations in ADHD across many different studies (see below).

The functions of the $\mathrm{PFc}$ and its regulation by DA and NE are here reviewed in two animal models, spontaneously hypertensive (SHR) and Naples High Excitability rats (NHE; see also for review Viggiano et al., 2002; Viggiano et al., 2003b).

\section{THE PFC IN ANIMAL MODELS OF ADHD}

\subsection{Functional anatomy and alterations}

The existence of a PFc in rodents has been widely debated (Brown \& Bowman, 2002; Uylings et al., 2003). In particular, the human PFc can be divided into different subregions, which share a common input represented by the mediodorsal thalamic nucleus (Uylings et al., 2003). In rats, however, the latter projects only to the medial and orbital frontal lobe, but not to dorsolateral regions.

The PFc has been involved in attention, decision making (Mulder et al., 2003), temporal organization of behavior (Fuster, 2000), working memory (Goldman-Rakic, 1996), and reversal learning (McAlonan \& Brown, 2003).

Functional subdivision of the $\mathrm{PFc}$ in rats, mainly based on lesion studies, comprises three 
main fields: medial (dorsal and ventral), orbitofrontal, and dorsolateral. Lesions of the rat medial PFc impair attention and attentional set shift (Brown \& Bowman, 2002; Uylings et al., 2003), reduce anxiety, and increase novelty-induced locomotor activity (Deacon et al., 2003). Lesions of the dorsomedial (anterior cingulate) PFc impair discriminative accuracy, whereas the ventromedial (infralimbic) region sustains inhibitory control (Chudasama et al., 2003). Orbitofrontal lesions impair behavioral flexibility, leading to perseverative tendencies, thus decreasing performance in various learning and memory tasks (Chudasama et al., 2003; Vafaei \& Rashidy-Pour, 2004). Lesions of the dorsolateral PFc lead to shifting strategy alterations, impairing behavioral flexibility in rats. Conversely, a corresponding lesion in humans impairs working memory.

The activity of the PFc is modulated by a set of subcortical systems comprising acetylcholine-, DA-, 5-hydroxytryptamine (5-HT)-, NE-, and histaminecontaining neurons (Robbins, 1997; Uylings et al., 2003). Recently, a sixth system has been characterized, originating from the lateral hypothalamus, which releases glutamate and orexin (also called hypocretin) as neuromodulators (Torrealba et al., 2003). All derive from a relatively small number of neurons with a terminal arborization that allows the innervation of the entire forebrain and spinal cord. These subcortical systems partially share target regions and influence each other in a very complex manner. In particular, NE neurons from the LC project to almost the entire neocortex, and the NE terminals are denser in layers IV and V, although the laminar distribution is less evident in rodents (Foote et al., 1987). Th is widespread input to the cortex differs from the DA input, which is restricted at the cortical level to the medial PFc (Bjorklund \& Lindvall, 1984). The only cortical areas that project back to the LC are the same medial PFc in rats and the dorso-lateral PFc in primates (Arnsten, 1997). Interestingly, the orexin system also interacts with both DA (Fadel \&
Deutch, 2002) and NE systems (Monda et al., 2004). Finally, the PFc receives input also and projects back to the reticular formation (Newman et al., 1989; Gritti et al., 1997).

Electrophysiological evidence shows that PFc neurons are activated during the delay period of a delayed-response trial (see Goldman-Rakic, 1996), thus suggesting its involvement in working memory functions. Recent data would also suggest a direct involvement in reward-directed learning. In fact, neurons in the PFc increase their firing rate at the presentation, whereas they reduce the firing rate from the conditioned-stimulus presentation up to the reward delivery, after the task has been learnt (Mulder et al., 2003). Thus, the PFc has access to reward stimuli. In fact, a loop has been anatomically and functionally described, involving the PFc, striatum, globus pallidum, and substantia nigra (the striatal output), the thalamus (ventromedial nucleus), and back to the PFc (Uylings et al., 2003). This circuit is thought to link motivationally relevant stimuli to motor areas (Kalivas et al., 1993). The electrophysiological data reported above rather suggest, however, that PFc neurons encode for prediction in reward delivery and transfer this information directly to the VTA, where the error in prediction is calculated (Williams et al., 2004).

Interestingly, the process of error prediction is possibly altered in ADHD, thus suggesting a direct involvement of PFc modulation in this disorder. More direct evidence of an involvement of the PFc in $\mathrm{ADHD}$ is the following:

- reduced volume of right PFc (Hynd et al., 1990; Castellanos et al., 1996; Filipek et al., 1997; Pueyo et al., 2000; Mostofsky et al., 2002),

- reduced activation of right prefrontal metabolism during response inhibition tasks (Rubia et al., 2000; Langleben et al., 2001), and

- reduced $\left[\mathrm{F}^{18}\right]$-DOPA uptake ratios in the medial PFC.

Moreover, the analysis of the PFc in animal models of ADHD reveals similar alterations in the 
PFc. In fact, rats selected over a mixed population for their impulsivity in an attentive task show a lower metabolic activation of the PFc (Barbelivien et al., 2001). In addition, the PFc of SHR compared with Wistar Kyoto (WKY) control rats shows (a) a reduced number of tyrosine hydroxylase (TH) fibers (King et al., 2000) and (b) increased NE activity in the PFc (Russell, 2000).

\subsection{Modulation of PFc functions by NE and DA}

The PFc receives projections from both the VTA and the LC and sends back projections to the VTA and to regions where dendrites of NE LC cells are present (Jodo et al., 1998). In fact, several data (see e.g. Jodo et al., 1998) show that the PFc is a major source of excitation of the LC.

Strikingly, DA does not modulate NE release in the PFc (Vanderschuren et al., 1999), whereas $\mathrm{NE}$ can modulate DA release (Bymaster et al., 2002). In fact, the excitation of LC neurons increases the release of DA in the PFc, but this effect does not occur through a direct excitation of DA neurons or terminals (Kawahara et al., 2001). A mechanism responsible in part for this effect is represented by the reuptake of DA by the NE transporter (NET) (Carboni et al., 1990). As a consequence, the NE terminals in the PFc would regulate the resting levels of DA through the NET. This offers an interpretation of the increase NE and DA levels in the PFc after treatment with drugs that block the NET, such as reboxetine and atomoxetine (Bymaster et al., 2002). In fact, the effects of psychostimulants such as D-amphetamine on DA outflow can be partially controlled by NE receptors (Darracq et al., 1998). The NE and DA systems, however, can also interact at the nuclei of origin and in other target sites.

\section{Dopamine and norepinephrine interactions}

Direct connections have been found between the VTA and the LC. In fact, DA neurons in the
VTA express $\alpha$-2c NE receptors (Lee et al., 1998), and there is a tonic release of NE in the VTA (Reith et al., 1997). Indeed, morphological evidence supports a direct projection from the LC to the VTA (Phillipson, 1979). In addition, direct projections from the VTA to the LC exist (Swanson, 1982) and are able to excite NE neurons (Deutch et al., 1986).

The nucleus accumbens is the target of DA neurons from the VTA and NE neurons from the nucleus tractus solitarius (NST) (Berridge \& Waterhouse, 2003). Thus, local injection of adrenoceptor agonists modulates DA release (Yavich et al., 1997), and, conversely, DA modulates the release of NE (Vanderschuren et al., 1999). These interactions at the nuclei of origin and target sites and the DA reuptake by the NET make it difficult to disentangle the behavioral effects of NE and DA drugs. In particular, inferences about the pathogenesis of ADHD based on the efficacy of drugs acting on the NE system should be advanced with caution. To this aim, the behavioral effects of genetic manipulation of the $\mathrm{NE}$ system and the changes in the NE system evidenced in animal models of ADHD are discussed.

\section{BIOCHEMICAL/BEHAVIORAL EFFECTS OF CHANGES IN THE NE SYSTEM}

\subsection{Embryogenesis}

The use of knock out (KO) technology has been used to explain many functional aspects of NEergic neurons (for review see Carson \& Roberson, 2002; see Table 1 for a summary). The LC neurons are strictly regulated during their development, although the regulatory cascade is not yet fully defined. Homeobox gene Phox2adeficient mice show an absence of the LC and defects in sensory/ autonomic ganglia (Morin et al., 1997). Therefore, the homeodomain protein 
TABLE 1

Knockout and transgenic mice for norepinephrine system

\begin{tabular}{|c|c|c|c|c|c|}
\hline $\begin{array}{l}\text { Gene }(--=\mathrm{KO} \\
++=\text { over- } \\
\text { expression })\end{array}$ & DA levels & $\begin{array}{c}\mathrm{NE} \\
\text { levels }\end{array}$ & $\begin{array}{l}\text { Sensitivity to } \\
\text { amphetamines }\end{array}$ & Locomotor activity & References \\
\hline Phox2a -- & & & & $\begin{array}{l}\text { No development of } \\
\text { NE system }\end{array}$ & (Morin, 1997) \\
\hline Mash-1 -- & & & & $\begin{array}{c}\text { No development of } \\
\text { NE system }\end{array}$ & (Hirsch, 1998) \\
\hline TH -- & $<$ & $<$ & & $<$ & $\begin{array}{l}\text { (Kobayashi, 1995; } \\
\text { Zhou, 1995) } \\
\end{array}$ \\
\hline TH -- + DBH & $<$ & - & & $<$ & (Zhou, 1995) \\
\hline DBH -- & $>$ & $<$ & $>$ & - & (Thomas, 1997) \\
\hline $\mathrm{DBH}++$ & & - & & & (Kobayashi, 1994) \\
\hline VMAT2 -- & $>$ & & $>$ & & (Takahashi, 1997) \\
\hline NET -- & $<$ & $>$ & $>$ & $<$ & $(\mathrm{Xu}, 2000)$ \\
\hline Orct3 -- & - & - & & - & (Zwart, 2001) \\
\hline COMT & $>$ & - & & & (Gogos, 1998) \\
\hline MAO-A & $>$ & $>$ & & & (Cases, 1998) \\
\hline MAO-B & - & - & & & (Carson, 2002) \\
\hline$\alpha 1 b--$ & - & $<$ & $>$ & $>$ & (Drouin, 2002) \\
\hline$\alpha 1 b++$ & & $<$ & & $<$ & (Zuscik, 2000) \\
\hline$\alpha 1 \mathrm{~d}--$ & & & & $\begin{array}{l}\text { Impaired response to } \\
\text { noxious stimuli }\end{array}$ & (Tanoue, 2002) \\
\hline$\alpha 2 a-$ & & $>$ & & (2) & $\begin{array}{l}\text { (Schramm, 2001; } \\
\text { Lahdesmaki, 2002; } \\
\text { Davies, 2003) }\end{array}$ \\
\hline$\alpha 2 c-$ & $<$ & & $>$ & $>$ & (Sallinen, 1999) \\
\hline$\alpha 2 c++$ & & & & $<$ & (Sallinen, 1999) \\
\hline \multicolumn{6}{|c|}{$\begin{array}{l}\mathrm{KO}=\text { knockout, } \mathrm{DA}=\text { dopamine, } \mathrm{NE}=\text { norepinephrine } \\
-: \text { no changes; }>: \text { increased; }<: \text { decreased }\end{array}$} \\
\hline
\end{tabular}


Phox2a controls NEergic traits during development, possibly through an interaction with Mash-1, a gene transiently expressed in the central nervous system. In fact, the targeted mutation of Mash-1 also causes the absence of central and peripheral NE neurons (Hirsch et al., 1998). Knockout (KO) mice have been useful for dissecting the cascade that controls the NE phenotype.

\subsection{Synthesis and clearance}

Norepinephrine is synthesized from L-dihydroxyphenylalanine (L-DOPA), which is first converted to DA by the enzyme tyrosine hydroxylase (TH) and then to NE, through the action of the enzyme DA-beta-hydroxylase. Therefore, perturbations in TH (see below, TH KO) will affect the synthesis of both NE and DA. In fact, TH KO mice lack both DA and NE (Kobayashi et al., 1995; Zhou, 1995a). The animals survive embryogenesis but die at 3 to 4 weeks of age from severe hypoactivity and hypophagia. The synthesis of NE, however, can be normalized by the transgenic expression of TH under the control of the DA-b-hydroxylase promoter, thus generating pure DA KO mice. Such mice survive, displaying normal NE synthesis, but make no DA (Zhou, 1995a) and are severely hypoactive. Unfortunately, no data are available about their sensitivity to amphetamines.

Interestingly, the induction of a mutation in the TH gene, which leads to a $40 \%$ reduction in $\mathrm{TH}$ activity, leads to a lowered learning performance and memory formation. In these animals, spatial learning and LTP are normal, and the performance in behavioral tasks can be restored by stimulating NE activity (Kobayashi et al., 2000). Therefore, low levels of NE reduce motivation and performance in learning tasks.

On the other hand, DA beta-hydroxylase (DBH) KO mice, which selectively lack NE (Thomas \& Palmiter, 1997), do not show alterations in locomotor activity or learning, although they swim more slowly and show more rapid extinction. These animals show characteristic somatic problems such as ptosis, reduced body mass, hypotension, increased embryonic mortality, and deficient thermogenesis (Carson \& Roberson, 2002). Interestingly, DA levels are elevated in most tissues (Thomas et al., 1998). The mice are hypersensitive to the behavioral effects of amphetamine (Weinshenker et al., 2002) and susceptible to seizure-inducing stimuli (Szot et al., 1999). Reboxetine and other antidepressants have no effect in DBH KO mice (Cryan et al., 2001), which confirms that all the indirect effects of these drugs necessitate the release of NE. Unfortunately, no data are available about the effectiveness of reboxetine or other NET blockers in DA KO mice, which could disentangle the NE-dependent effects from the DA-dependent effects.

Conversely, the hyperexpression of DBH in transgenic mice is not accompanied by changes in NE levels (Kobayashi et al., 1994). Therefore, it is possible that the hypolocomotor phenotype of $\mathrm{TH}$ $\mathrm{KO}$ mice is, rather, due to the changes in DA levels or to the lack of compensatory DA changes in DBH mice.

The vesicular monoamine transporter (VMAT2) stores monoamines, and particularly $\mathrm{NE}$, from the neuronal cytoplasm into vesicles. VMAT2 KO mice die by the second week after birth and show increased mortality, possibly from arrhythmias (Takahashi et al., 1997). Heart rate, body temperature, NET, DA transporter (DAT), adrenergic, and DAergic receptors are normal, but DA levels are increased, as is the sensitivity to amphetamines.

Clearance for NE is accomplished by the NE reuptake system or NET, by monoamine oxidases (MAO-A and MAO-B), and by catechol-O-methyltransferase (COMT) enzymes. Although the NET is the predominant transporter in neuronal tissue, a second process termed uptake- 2 is responsible for the removal of NE, accomplished by the protein extraneuronal monoamine transporter (EMT) or the organic cation transporter 3 (OCT-3). Finally, 
COMT methylates NE, thus forming normetanephrine, whereas the intraneuronal degradation of $\mathrm{NE}$ is accomplished by MAO-A and MAO-B.

Mice carrying a functional deletion of the NET (Xu et al., 2000) are viable and fertile. Disruption of the NET gene prolongs the clearance of NE and elevates its extracellular levels. Intracellular levels of NE are decreased in NET KO mice, however, suggesting that $\mathrm{NE}$ storage levels in neurons is controlled by reuptake rather than by synthesis. These animals are hypothermic. Moreover, they are less active than controls in an open field. This is accompanied by lower resting levels of DA, and supersensitive postsynaptic D2/D3 DA receptors, thus increasing the behavioral effects of amphetamine.

Knock out mice for the Orct3 gene, which encodes for the EMT (extraneuronal monoamine transporter, see above), display normal general behavior and normal levels of DA and NE (Zwart et al., 2001). Mice lacking COMT show increased levels of DA but not of NE (Gogos et al., 1998). Monoamine oxidase-A KO mice show increased levels of NE, 5-HT, DA in the CNS (Cases et al., 1998), and increased aggression. Conversely, MAO-B KO mice do not show differences in NE, 5-HT, and DA levels (Grimsby et al., 1997). All this evidence is in agreement with the hypothesis that MAO-A is the only oxidase in NE neurons in the LC.

In summary, lesions that reduce the extracellular NE level (DBH KO, VMAT2 KO mice) induce the compensatory hyperDAergic system, normal locomotor activity but hyperresponsivity to amphetamines. On the contrary, lesions that increase the intracellular NE level (NET KO mice) also decrease the DA level, accompanied by low locomotor activity and hypersensitivity to amphetamines. Finally, lesions that decrease both DA and NE levels (TH KO mice) reduce locomotor activity.

Thus, the NE and DA systems are regulated in a negative feedback manner. The levels of DA correlate with locomotor activity, whereas the responsivity to amphetamines is the outcome of a balance between the two systems. In fact, selective and extensive depletion of $\mathrm{NE}$ in neonatal rats by 6-OHDA in presence of a DAT inhibitor leads to increased expression of DA, motor hyperactivity, and distractability (Raskin et al., 1983; Carli et al., 1983).

\subsection{Receptors}

The NE receptors have been classified in three classes: alpha $a_{1}$ receptors, which are at postsynaptic sites, alpha ${ }_{2}$ receptors, both pre- and postsynaptic, and three different beta receptors, which are mainly postsynaptic but can also act presynaptically to facilitate NE release (O'Donnell, 1993; Murugaiah \& O'Donnell, 1995). A fourth beta receptors isoform has been hypothesized recently (Oostendorp et al., 2000), The fourth group, beta receptors, represents an important interface between the sympathetic nervous system and the cardiovascular system (the so called betaadrenergic axis; see Naga Prasad et al., 2001). As far as beta receptor $\mathrm{KO}$ mice are concerned, they are not included in this review because most of their alterations pertain to the heart.

Three $\alpha_{1}$ subtypes $\left(\alpha_{1 \mathrm{a}}, \alpha_{1 \mathrm{~b}}, \alpha_{1 \mathrm{~d}}\right)$ and four $\alpha_{2^{-}}$ receptor subtypes $\left(\alpha_{2 \mathrm{a}-\mathrm{d}}\right)$ are described. These are also expressed on glial cells, and their expression is different according to the brain region, $\alpha_{1 \mathrm{a}}$ being expressed mainly in the ventral part of the brain, $\alpha_{1 b}$ in the thalamus, amygdala and raphe nuclei and $\alpha_{1 \mathrm{~d}}$ in the cortex and hippocampus (see also Tanoue et al., 2002). Here, synapses are present on both pyramidal and nonpyramidal neurons, on which the $\alpha_{2 a}$ receptor is the predominant NE receptor isoform (Aoki et al., 1998). Mice lacking the $\alpha_{1 \mathrm{ab}}, \alpha_{1 \mathrm{~b}}, \alpha_{1 \mathrm{~d}}, \alpha_{2 \mathrm{a}}, \alpha_{2 \mathrm{~b}}, \alpha_{2 \mathrm{c}}$ adrenergic receptor subtypes and a mouse line containing a point mutation in the $\alpha_{2 \mathrm{a}}$ receptor have been developed. Moreover, lines overexpressing the $\alpha_{1 \mathrm{a}}, \alpha_{1 \mathrm{~b}}, \alpha_{1 \mathrm{~d}}$ receptors under the control of different promoters have been studied (Sallinen et al., 1999; Tanoue et 
al., 2002; Drouin et al., 2002). Only one subset of these lines has been behaviorally tested. None of the $\alpha_{1}$ subtypes is required for embryologic development, as these $\mathrm{KO}$ mice do not show gross abnormalities.

Mice KO for $\alpha_{1 b}$ show increased reaction to novelty and novelty-induced hyperactivity (Spreng et al., 2001) although other reports failed to confirm this evidence (Drouin et al., 2002). Moreover, KO mice do not display changes in the DA system, but the levels of NE in the PFc are lower than those in wild-type mice. The locomotion-stimulating effects and the increase in DA levels induced by d-amphetamine-morphine are decreased in these animals (Drouin et al., 2002; Auclair et al., 2002). This reduction might depend on a lower efflux of DA after stimulation (Battaglia et al., 2003).

Conversely, mice overexpressing the $\alpha_{1 b}$ receptor have an age-dependent loss in horizontal deambulation and a reduced number of rearings, which can improve after treatment with adrenergic blockers or with L-DOPA (Zuscik et al., 2000). Moreover, this phenotype is accompanied by seizures and neurodegeneration, and NE plasma levels are reduced.

Mice lacking the $\alpha_{1 d}$ receptor show an impaired response to noxious stimuli (Tanoue et al., 2002). Mice lacking the $\alpha_{2 \mathrm{a}}$ receptor show normal locomotor activity (Schramm et al., 2001) but a reduced number of rearings in open field (Lahdesmaki et al., 2002).The resting levels of NE are normal, but the NE turnover is increased (Lahdesmaki et al., 2002), and the NE LC neurons are hypertrophic (Davies et al., 2003). Anxiety tests in these animals suggest that $\alpha_{2 \mathrm{a}}$ is stress protecting (Schramm et al., 2001).

Targeted inactivation of the $\alpha_{2 c}$ receptor leads to normal or increased locomotor activity, and supersensitivity to amphetamine (Sallinen et al., 1999). Moreover, these mice exhibit lower DA turnover. Conversely, transgenic mice overexpressing $\alpha_{2 c}$ receptors show normal or reduced activity and increased stress susceptibility. Anxiety tests in these animals suggest that $\alpha_{2 c}$ mediates stress susceptibility (Schramm et al., 2001).

Interestingly, methylphenidate, a drug that blocks the DA transporter and is widely used in ADHD pharmacotherapy, decreases the collected reward in an operant conditioning task in normal mice, but has opposite effect in $\alpha_{2 c}$ receptor KO mice (Ihalainen et al., 2001). This is in agreement with the increase in spontaneous locomotor activity induced by amphetamine in these animals. It is plausible that the alteration in DA metabolism can explain the different effect of MPH (see also the companion paper by Viggiano et al., 2004 this issue).

In summary, both $\alpha_{1 b}$ and $\alpha_{2 c}$ receptors control locomotor activity; KO mice for these receptors show increased activity, whereas transgenic overexpressing mice show decreased activity. Their influence on DA and NE levels is different. The $\alpha_{1 b}$ KO mice do not show changes in DA level but have a lower NE level than the wild-type, whereas $\alpha_{2 c}$ KO mice show a lower DA turnover. The sensitivity to amphetamines is again reflected by the balance between DA and NE levels.

\section{NOREPINEPHRINE SYSTEM CHANGES IN BEHAVIORAL MODELS OF ADHD}

Many data are available about the NE system in an animal model of ADHD, the SHR. These mice are hyperactive and impulsive in comparison with their WKY controls. The evidence from LC neurochemistry does not show an alteration in NE levels (Kaehler et al., 2000), although the turnover can be elevated. The firing rate of these neurons is normal (Conti et al., 1997) or lower (Olpe et al., 1985). The TH levels are increased in the medulla (Kumai et al., 1996, 2003) and around vessels (Gradin et al., 2003) but decreased in the PFc (King et al., 2000). Recent data also report lower amounts of TH in a bounded postnatal period (Leo et al., 2003). The NE levels are normal in the 
solitary tract (Dev \& Philip, 1996) but elevated in the median preoptic area (Tanaka et al., 2002), striatum and brainstem (Howes et al., 1984). The release of NE per varicosity might be increased (Jimenez-Altayo et al., 2003). The $\alpha_{1}$ receptors in the cortex of SHR are increased (Hellstrand \& Engel, 1980), a datum that contrasts with the hypoactivity of $\alpha_{1 b}$ over-expression in mice. Some of these alterations might explain the elevated blood pressure in these animals, but do not correlate with the hyperactivity (Reja et al., 2002).

The data presented in Table 2 raise the question about why ADHD subjects respond to pharmacological agents that modify the NE system. In order to address this point, we will show data about the biochemical and behavioral effects of NET blockers and revise these effects from the view-point of an alteration in the attentional networks.

\section{NET BLOCKADE IN HYPERACTIVE RATS}

\subsection{Norepinephrine and dopamine systems}

Reboxetine and atomoxetine are potent and selective inhibitors of the NET (Wong et al., 2000). In contrast, the affinity of the psychostimulant methylphenidate is higher for the DAT than for the NET (Bymaster et al., 2002). Reboxetine and atomoxetine exert a similar action on the levels of NE and DA in the PFc, but differ as regards the effects on 5-HT levels. In fact, both reboxetine and atomoxetine enhance DA output in the PFc, but not in the accumbens (Kuczenski \& Segal, 1995; Wong et al., 2000). Possibly this effect is dependent on a blockade of DA reuptake by the NET in the PFc, a mechanism absent in the striatum, where NE terminals are few (Carboni et al., 2003). It is possible, however, that indirect mechanisms intervene, as $\alpha_{2}$-adrenergic antagonists also increase DA release in terminal fields (Shi et al., 2000; Linner et al., 2001).
The increased DA level is accompanied by an increased burst firing but not an average firing frequency of DA cells in the VTA (Linner et al., 2001). Similar changes might be responsible for altered reward perception, with a mechanism similar to methylphenidate (see also companion paper (Viggiano et al., 2004 - this issue).

Similarly, the blockade of NET by these drugs increases the levels of NE (Kuczenski \& Segal, 1995). High doses lead to a reduction of the firing rate of LC NE cells and 5-HT cells in a dosedependent relation (Wong et al., 2000), an effect similar to that of other stimulants (Aston-Jones \& Bloom, 1981). Interestingly, $\alpha_{2}$-adrenergic antagonists and methylphenidate (Kuczenski \& Segal, 2001) also enhance NE release (Thomas, 1991). Reboxetine does not lead to increased extracellular levels of 5-HT (Kuczenski \& Segal, 1995).

Similar studies with atomoxetine show that specific PFc modulators have a different sensibility to these drugs. In fact, NE is already increased at low doses $(0.3 \mathrm{mg} / \mathrm{kg})$, whereas DA is increased at medium doses $(1 \mathrm{mg} / \mathrm{kg})$ and $5-\mathrm{HT}$ at high doses $(3 \mathrm{mg} / \mathrm{kg})$ (Bymaster et al., 2002). The maximal release occurs 1 hour after injection. Interestingly, the effects on DA are evident only in the PFc, as no changes can be detected in the striatum.

\subsection{Behavior}

Nowadays, low-doses of AMPH-like stimulants and methylphenidate are the main pharmacological treatment of ADHD. These drugs ameliorate the symptoms of inattentiveness, hyperactivity, and impulsivity. Unfortunately, about 10 to 30 percent of ADHD children are either non-responders or intolerant to psychostimulant therapy (Barkley, 1977), which may reflect the heterogeneous neural substrates of ADHD.

Other therapies primarily affect the NE system, thus indirectly modulating the DA system. In fact, NE $\alpha_{2}$-agonists like guanfacine (Hunt et al., 1995) are also effective in the treatment of the disorder. 
TABLE 2

Changes of the norepinephrine system in SHR rats

\begin{tabular}{|c|c|}
\hline $\mathbf{L C}$ & \\
\hline NE content in LC & - (Kaehler, 2000) \\
\hline Release of NE in LC & - (Kaehler, 2000) \\
\hline NE turnover in LC & $>$ (Kaehler, 2000) \\
\hline Firing rate of $\mathrm{LC}$ neurons & $\begin{array}{l}\text { (Conti, 1997) } \\
<\text { (Olpe, 1985) }\end{array}$ \\
\hline $\mathrm{NE}$ in striatum, brainstem & $>^{\text {(Howes, 1984) }}$ \\
\hline Release of 5-HT & $>^{\text {(Reja, 2002) }}$ \\
\hline TH in medulla oblongata & $>$ (Kumai, 1996) \\
\hline TARGETS & \\
\hline NE content of Nucleus of the solitary tract & - (Dev, 1996) \\
\hline $\mathrm{TH}+$ fibers in frontal cortex & $<^{\text {(King, 2000) }}$ \\
\hline NE release in Median preoptic area & $>^{\text {(Tanaka, 2002) }}$ \\
\hline Inhibition of NE Release by $\alpha-2$ receptors & $<^{\text {(Russell, 2000) }}$ \\
\hline NE release per varicosity & $>^{\text {(Jimenez-Altayo, 2003) }}$ \\
\hline TH fibers around vessels & $>^{(\text {Gradin, 2003) }}$ \\
\hline TH activity in adrenal medulla & $>^{\text {(Reja, 2002; Kumai, 2003) }}$ \\
\hline Alfa- 1 receptors in cortex & $>^{\text {(Hellstrand, 1980) }}$ \\
\hline Correlation of TH gene expression of blood pressure & Positive ${ }^{(\text {Reja, 2002) }}$ \\
\hline
\end{tabular}

TABLE 3

\begin{tabular}{|c|c|c|c|c|}
\hline \multicolumn{5}{|c|}{ Behavioral effects of Reboxetine } \\
\hline & SHR & WKY & NHE & NRB \\
\hline Number of rearings & - & $<(-47 \%)$ & $<(-19 \%)$ & - \\
\hline Horizontal activity & $<(-25 \%)$ & $<(-40 \%)$ & - & - \\
\hline $\begin{array}{l}\text { Duration of } \\
\text { rearings }\end{array}$ & $>(+26 \%)$ & $>(+17 \%)$ & - & $>(+22 \%)$ \\
\hline \multicolumn{5}{|c|}{ Behavioral effects of Atomoxetine } \\
\hline Number of rearings & not tested & not tested & $<(-27 \%)$ & - \\
\hline Horizontal activity & not tested & not tested & $<(-17 \%)$ & - \\
\hline $\begin{array}{l}\text { Duration of } \\
\text { rearings }\end{array}$ & not tested & not tested & - & - \\
\hline
\end{tabular}


Finally, antidepressants like reboxetine and atomoxetine have also been used. In particular, atomoxetine (tomoxetine, LY139603) is effective in treating ADHD in adults (Spencer et al., 1998).

To study the differential effects of NET blockers in normal and hyperactive rats, we used two animal models of hyperactivity and attention deficit, previously characterized by a hyperfunctioning mesocorticolimbic (SHR) or mesocortical (NHE) DA system (Viggiano et al., 2000, 2003a,b). To this aim, male SHR and NHE rats, with WKY and Naples Random Bred (NRB) rats as their respective controls, received daily i.p. injections of the NE reuptake inhibitor reboxetine (Pharmacia Upjohn, Milano, Italy, $10 \mathrm{mg} / \mathrm{kg}$ ) or atomoxetine (Lilly, $1 \mathrm{mg} / \mathrm{kg}$ ) for 14 days. Rats were tested in a spatial novelty (Làt-maze) $90 \mathrm{~min}$ after the last injection of drug or vehicle. The behavioral test lasted for 30 minutes, during which it was videotaped and analyzed off-line for indices of activity (traveled distance, rearing frequency) and non-selective attention (scanning durations).

In SHR and control rats (WKY), reboxetine induced a significant reduction in traveled distance compared with vehicle-treated controls $(-25 \%$ and $-40 \%$ respectively). This reduction mainly pertained to the first 15 minutes of exploration. In contrast, reboxetine did not reduce the traveled distance in NHE rats nor in NRB controls.

Reboxetine reduced the orienting frequency only in WKY rats ( $-47 \%$ compared with vehicle), without effects on SHR rats. In contrast, the drug reduced the frequency of rearings in NHE $(-19 \%)$ but not in NRB rats. Reboxetine increased the duration of rearing episodes in both SHR and WKY rats $(+25 \%$ and $+17 \%$ respectively). In contrast, the drug increased the duration of rearings in NRB $(+22 \%)$ but not in NHE rats. Therefore, the net effects were different if we consider the number of rearings, the horizontal exploratory activity, or the duration of rearing episodes. The number of rearing was decreased, but only in NHE and WKY rats, whereas SHR and
NRB rats did not show any change. In SHR and WKY rats, reboxetine reduced horizontal activity and prolonged scanning time. In contrast, in NHE and NRB rats reboxetine increased rearing durations in the control line, whereas it decreased the rearing frequency in NHE rats. Similarly, atomoxetine did not modify the horizontal and vertical activity of NRB rats, whereas it reduced the number of rearings $(-27 \%)$ and the traveled distance $(-17 \%)$, without effects on scanning durations in NHE rats (see Table 3).

The data suggest different activity of the NE system in the SHR versus NHE lines. In fact, SHR and NHE rats have different responses, reflecting different neural substrates. The differential sensitivity of these two lines to reboxetine could be due to a different involvement of the DA and $\mathrm{NE}$ systems in these animals. Although the effects of the NET blockade are similar in both the hyperactive SHR and the control rats, the main effects are evident in NHE rats, but not in their NRB controls.

The overall results would suggest that the NE system is similar in SHR and WKY rats, whereas differences exist between NHE and NRB rats. Alternatively, the interaction between the NE and DA systems is altered in NHE rats. These conclusions are in agreement with previous suggestions that an alteration of the NE system in adult SHR rats is indeed linked to the hypertensive phenotype but not to hyperactivity.

As both the NE and the DA systems are involved in arousal, attention, and cognitive functions, the drugs may act on two different pathways, thus changing the level of motivation (Wong et al., 2000). In fact, the LC-NE system is sensitive to novel environmental stimuli. An enhanced NE neurotransmission in a novel environment (see Làt maze) decreases attention to an individual object, increasing the scanning of the environment (Berridge \& Waterhouse, 2003).

Therefore, the lower frequency of rearings and the increase of their duration in NHE rats may 
indicate a lower firing rate of $\mathrm{LC}$ neurons, whereas the changes in SHR and WKY rats can be explained by the involvement of other systems, such as DA. The data lead to the suggestion that the positive effects of NEergic drugs may be due to an indirect action on the DA system. Nonetheless, further research is warranted by these findings to disentangle this intricate issue.

\section{ACKNOWLEDGMENTS}

This research has been supported by grant from MIUR-COFIN 2001/2002 and Ministry of Health-Special Funds.

\section{REFERENCES}

American Psychiatric Association, Task Force on DSM-IV. 2004. Diagnostic and Statistical Manual of Mental Disorders DSM-IV-TR (Text Revision). Washington DC, USA: APA.

Aoki C, Venkatesan C, Go CG, Forman R, Kurose H. 1998. Cellular and subcellular sites for noradrenergic action in the monkey dorsolateral prefrontal cortex as revealed by the immunocytochemical localization of noradrenergic receptors and axons. Cereb Cortex 8: 269-277.

Arnsten AF. 1997. Catecholamine regulation of the prefrontal cortex. J Psychopharmacol 11: 151-162.

Aston-Jones G, Bloom FE. 1981. Activity of norepinephrine-containing locus coeruleus neurons in behaving rats anticipates fluctuations in the sleep-waking cycle. J Neurosci 1: 876-886.

Auclair A, Cotecchia S, Glowinski J, Tassin JP. 2002. D-amphetamine fails to increase extracellular dopamine levels in mice lacking alpha $1 \mathrm{~b}$ adrenergic receptors: relationship between functional and nonfunctional dopamine release. $\mathrm{J}$ Neurosci 22: 9150-9154.

Barbelivien A, Ruotsalainen S, Sirvio J. 2001. Metabolic alterations in the prefrontal and cingulate cortices are related to behavioral deficits in a rodent model of attention-deficit hyperactivity disorder. Cereb Cortex 11: 1056-1063.
Barkley RA. 1977. A review of stimulant drug research with hyperactive children. J Child Psychol Psychiatry 18: 137-165.

Battaglia G, Fornai F, Busceti CL, Lembo G, Nicoletti F, De Blasi A. 2003. Alpha-1B adrenergic receptor knockout mice are protected against methamphetamine toxicity. J Neurochem 86: 413-421.

Berridge CW, Waterhouse BD. 2003. The locus coeruleus-noradrenergic system: modulation of behavioral state and state-dependent cognitive processes. Brain Res Brain Res Rev 42: 33-84.

Biederman J, Spencer T. 1999. Attention-deficit/ hyperactivity disorder (ADHD) as a noradrenergic disorder. Biol Psychiatry 46: 1234-1242.

Bjorklund A, Lindvall O. 1984. Dopamine containing systems in the CNS. In: Bjorklund A, Hokfelt T, eds, Handbook of Chemical Neuroanatomy. Amsterdam, the Netherlands: Elsevier; 55-122.

Bouret S, Sara SJ. 2002. Locus coeruleus activation modulates firing rate and temporal organization of odour-induced single-cell responses in rat piriform cortex. Eur J Neurosci 16: 2371-2382.

Brown VJ, Bowman EM. 2002. Rodent models of prefrontal cortical function. Trends Neurosci 25: 340-343.

Bymaster FP, Katner JS, Nelson DL, Hemrick-Luecke SK, Threlkeld PG, et al. 2002. Atomoxetine increases extracellular levels of norepinephrine and dopamine in prefrontal cortex of rat: a potential mechanism for efficacy in attention deficit/hyperactivity disorder. Neuropsychopharmacology 27: 699-711.

Carboni E, Silvagni A, Valentini V, Di Chiara G. 2003. Effect of amphetamine, cocaine and depolarization by high potassium on extracellular dopamine in the nucleus accumbens shell of SHR rats. An in vivo microdyalisis study. Neurosci Biobehav Rev 27: 653-659.

Carboni E, Tanda GL, Frau R, Di Chiara G. 1990. Blockade of the noradrenaline carrier increases extracellular dopamine concentrations in the prefrontal cortex: evidence that dopamine is taken up in vivo by noradrenergic terminals. $J$ Neurochem 55: 1067-1070.

Carli M, Robbins TW, Evenden JL, Everitt BJ. 1983. Effects of lesions to ascending noradrenergic neurones on performance of a 5-choice serial reaction task in rats; implications for theories of dorsal noradrenergic bundle function based on 
selective attention and arousal. Behav Brain Res 9: 361-380.

Carson RP, Robertson D. 2002. Genetic manipulation of noradrenergic neurons. J Pharmacol Exp Ther 301: 410-417.

Cases O, Lebrand C, Giros B, Vitalis T, De Maeyer E, Caron MG, et al. 1998. Plasma membrane transporters of serotonin, dopamine, and norepinephrine mediate serotonin accumulation in atypical locations in the developing brain of monoamine oxidase A knock-outs. J Neurosci 18: 6914-6927.

Castellanos FX, Giedd JN, Marsh WL, Hamburger SD, Vaituzis AC, Dickstein DP, et al. 1996. Quantitative brain magnetic resonance imaging in attention-deficit hyperactivity disorder. Arch Gen Psychiatry 53: 607-616.

Castellanos FX, Tannock R. 2002. Neuroscience of Attention-Deficit/Hyperactivity Disorder: the search for endophenotypes. Nature Reviews 3: 617-628.

Cerbone A, Sadile AG. 1994. Behavioral habituation to spatial novelty: interference and noninterference studies. Neurosci Biobehav Rev 18: 497-518.

Chudasama Y, Passetti F, Rhodes SE, Lopian D, Desai A, Robbins TW. 2003. Dissociable aspects of performance on the 5-choice serial reaction time task following lesions of the dorsal anterior cingulate, infralimbic and orbitofrontal cortex in the rat: differential effects on selectivity, impulsivity and compulsivity. Behav Brain Res 146: 105-119.

Conti LH, Youngblood KL, Printz MP, Foote SL. 1997. Locus coeruleus electrophysiological activity and responsivity to corticotropin-releasing factor in inbred hypertensive and normotensive rats. Brain Res 774: 27-34.

Cryan JF, Dalvi A, Jin SH, Hirsch BR, Lucki I, Thomas SA. 2001. Use of dopamine-betahydroxylase-deficient mice to determine the role of norepinephrine in the mechanism of action of antidepressant drugs. J Pharmacol Exp Ther 298: 651-657.

Dahlstrom A, Fuxe K. 1964. Evidence for the existence of monoamine-containing neurons in the central nervous system. I. Demonstration of monoamines in cell bodies of brain stem neurons. Acta Physiol Scand 62 Suppl 232: 1-55.

Dalen L, Sonuga-Barke EJ, Hall M, Remington B. 2004. Inhibitory deficits, delay aversion and preschool $\mathrm{AD} / \mathrm{HD}$. implications for the dual pathway model. Neural Plast 11:1-12.

Darracq L, Blanc G, Glowinski J, Tassin JP. 1998. Importance of the noradrenaline-dopamine coupling in the locomotor activating effects of Damphetamine. J Neurosci 18: 2729-2739.

Davies MF, Tsui JY, Flannery JA, Li X, DeLorey TM, Hoffman BB. 2003. Augmentation of the noradrenergic system in alpha-2 adrenergic receptor deficient mice: anatomical changes associated with enhanced fear memory. Brain Res 986: 157-165.

Deacon RM, Penny C, Rawlins JN. 2003. Effects of medial prefrontal cortex cytotoxic lesions in mice. Behav Brain Res 139: 139-155.

Deutch AY, Goldstein M, Roth RH. 1986. Activation of the locus coeruleus induced by selective stimulation of the ventral tegmental area. Brain Res 363: 307-314.

Dev BR, Philip L. 1996. Extracellular catechol and indole turnover in the nucleus of the solitary tract of spontaneously hypertensive and Wistar-Kyoto normotensive rats in response to drug-induced changes in arterial blood pressure. Brain Res Bull 40: 111-116.

Drouin C, Darracq L, Trovero F, Blanc G, Glowinski J, Cotecchia S, Tassin JP. 2002. Alphalb-adrenergic receptors control locomotor and rewarding effects of psychostimulants and opiates. J Neurosci 22: 2873-2884.

Fadel J, Deutch AY. 2002. Anatomical substrates of orexin-dopamine interactions: lateral hypothalamic projections to the ventral tegmental area. Neuroscience 111: 379-387.

Fallon JH, Loughlin SE. 1982. Monoamine innervation of the forebrain: collateralization. Brain Res Bull 9: 295-307.

Filipek PA, SemruD-Clikeman M, Steingard RJ, Renshaw PF, Kennedy DN, Blederman J. 1997. Volumetric MRI analysis comparing attentiondeficit hyperactivity disorder and normal controls. Neurology 48: 589-601.

Foote SL, Bloom FE, Aston-Jones G. 1983. Nucleus locus ceruleus: new evidence of anatomical and physiological specificity. Physiol Rev 63: 844914.

Foote SL, Morrison JH. 1987. Extrathalamic modulation of cortical function. Annu Rev Neurosci 10: 67-95.

Fuster JM. 2000. Executive frontal functions. Exp Brain Res 133: 66-70. 
Gogos JA, Morgan M, Luine V, Santha M, Ogawa S, Pfaff D, Karayiorgou M. 1998. Catechol-Omethyltransferase-deficient mice exhibit sexually dimorphic changes in catecholamine levels and behavior. Proc Natl Acad Sci USA 95: 9991-9996.

Goldman-Rakic PS. 1996. Regional and cellular fractionation of working memory. Proc Natl Acad Sci USA 93: 13473-13480.

Gradin KA, Li JY, Andersson O, Simonsen U. 2003. Enhanced neuropeptide $\mathrm{Y}$ immunoreactivity and vasoconstriction in mesenteric small arteries from spontaneously hypertensive rats. J Vasc Res 40: 252-265.

Grimsby J, Toth M, Chen K, Kumazawa T, Klaidman L, Adams JD, et al. 1997. Increased stress response and beta-phenylethylamine in MAOB-deficient mice. Nat Genet 17: 206-210.

Gritti I, Mainville L, Mancia M, Jones BE. 1997. GABAergic and other noncholinergic basal forebrain neurons, together with cholinergic neurons, project to the mesocortex and isocortex in the rat. J Comp Neurol 383: 163-177.

Hellstrand K, Engel J. 1980. Locomotor activity and catecholamine receptor binding in adult normotensive and spontaneously hypertensive rats. J Neural Transm 48: 57-63.

Hirsch MR, Tiveron MC, Guillemot F, Brunet JF, Goridis C. 1998. Control of noradrenergic differentiation and Phox $2 \mathrm{a}$ expression by MASH1 in the central and peripheral nervous system. Development 125: 599-608.

Howes LG, Rowe PR, Summers RJ, Louis WJ.1984. Age related changes of catecholamines and their metabolites in central nervous system regions of spontaneously hypertensive (SHR) and normotensive Wistar-Kyoto (WKY) rats. Clin Exp Hypertens A 6: 2263-2277.

Hunt RD, Arnsten AF, Asbell MD. 1995. An open trial of guanfacine in the treatment of attentiondeficit hyperactivity disorder. J Am Acad Child Adolesc Psychiatry 34: 50-54.

Hynd GW, SemruD-Clikeman M, Lorys A, Novey ES, Eliopulos D. 1990. Brain morphology in developmental dyslexia and attention deficit disorder/hyperactivity. Arch Neurol 47: 919-928.

Ihalainen JA, Tanila H, Scheinin M, Riekkinen P, Jr. 2001. alpha(2C)-Adrenoceptors modulate the effect of methylphenidate on response rate and discrimination accuracy in an operant test. Brain Res Bull 54: 553-557.
Jimenez-Altayo F, Giraldo J, McGrath JC, Vila E. Enhanced noradrenergic transmission in the spontaneously hypertensive rat anococcygeus muscle. Br J Pharmacol 2003. 140: 773-779.

Jodo E, Chiang C, Aston-Jones G. 1998. Potent excitatory influence of prefrontal cortex activity on noradrenergic locus coeruleus neurons. Neuroscience 83: 63-79.

Kaehler ST, Sinner C, Philippu A. 2000. Release of catecholamines in the locus coeruleus of freely moving and anaesthetized normotensive and spontaneously hypertensive rats: effects of cardiovascular changes and tail pinch. Naunyn Schmiedebergs Arch Pharmacol 361: 433-439.

Kalivas PW, Churchill L, Klitenick MA. 1993. The circuitry mediating the translation of motivational stimuli into adaptive motor responses. In: Kalivas PW, Barnes CD, ed, Limbic motor circuits and Neuropsychiatry. Boca Raton, Florida, USA: CRC Press; 237-275.

Kawahara H, Kawahara Y, Westerink BH. 2001. The noradrenaline-dopamine interaction in the rat medial prefrontal cortex studied by multi-probe microdialysis. Eur J Pharmacol 418: 177-186.

King JA, Barkley RA, Delville Y, Ferris CF. 2000. Early androgen treatment decreases cognitive function and catecholamine innervation in an animal model of ADHD. Behav Brain Res 107: 35-43.

Kobayashi K, Morita S, Mizuguchi T, Sawada H, Yamada K, Nagatsu I, et al. 1994. Functional and high level expression of human dopamine betahydroxylase in transgenic mice. J Biol Chem 269: 29725-29731.

Kobayashi K, Morita S, Sawada H, Mizuguchi T, Yamada K, Nagatsu I, et al. 1995. Targeted disruption of the tyrosine hydroxylase locus results in severe catecholamine depletion and perinatal lethality in mice. J Biol Chem 270: 27235-27243.

Kobayashi K, Noda Y, Matsushita N, Nishii K, Sawada H, Nagatsu T, et al. 2000. Modest neuropsychological deficits caused by reduced noradrenaline metabolism in mice heterozygous for a mutated tyrosine hydroxylase gene. J Neurosci 20: 2418-2426.

Kuczenski R, Segal DS. 2001. Locomotor effects of acute and repeated threshold doses of amphetamine and methylphenidate: relative roles of dopamine and norepinephrine. J Pharmacol Exp Ther 296: 876-883. 
Kuczenski R, Segal DS, Cho AK, Melega W. 1995. Hippocampus norepinephrine, caudate dopamine and serotonin, and behavioral responses to the stereoisomers of amphetamine and methamphetamine. J Neurosci 15: 1308-1317.

Kumai T, Oonuma S, Kitaoka Y, Tadokoro M, Kobayashi S. 2003. Biochemical and morphological characterization of spontaneously hypertensive hyperlipidaemic rats. Clin Exp Pharmacol Physiol 30: 537-544.

Kumai T, Tanaka M, Watanabe M, Nakura H, Tateishi T, Kobayashi S. 1996. Elevated tyrosine hydroxylase mRNA levels in medulla oblongata of spontaneously hypertensive rats. Brain Res Mol Brain Res 36: 197-199.

Lacroix D, Ferron A. 1988. Electrophysiological effects of methylphenidate on the coeruleocortical noradrenergic system in the rat. Eur $\mathrm{J}$ Pharmacol 149: 277-285.

Lahdesmaki J, Sallinen J, MacDonald E, Kobilka BK, Fagerholm V, Scheinin M. 2002. Behavioral and neurochemical characterization of alpha $(2 \mathrm{~A})$ adrenergic receptor knockout mice. Neuroscience 113: 289-299.

Langleben DD, Austin G, Krikorian G, Ridlehuber HW, Goris ML, Strauss HW. 2001. Interhemispheric asymmetry of regional cerebral blood flow in prepubescent boys with attention deficit hyperactivity disorder. Nucl Med Commun 22: 1333-1340.

Lee A, Wissekerke AE, Rosin DL, Lynch KR. 1998. Localization of alpha2C-adrenergic receptor immunoreactivity in catecholaminergic neurons in the rat central nervous system. Neuroscience 84 : 1085-1096.

Leo D, Sorrentino E, Volpicelli F, Eyman M, Greco D, Viggiano D, et al. 2003. Altered midbrain dopaminergic neurotransmission during development in an animal model of ADHD. Neurosci Biobehav Rev 27: 661-669.

Linner L, Endersz H, Ohman D, Bengtsson F, Schalling M, Svensson TH. 2001. Reboxetine modulates the firing pattern of dopamine cells in the ventral tegmental area and selectively increases dopamine availability in the prefrontal cortex. $\mathrm{J}$ Pharmacol Exp Ther 297: 540-546.

Loughlin SE, Foote SL, Fallon JH. 1982. Locus coeruleus projections to cortex: topography, morphology and collateralization. Brain Res Bull 9: 287-294.
Mason ST. 1981. Noradrenaline in the brain: Progress in theories of behavioral function. Prog Neurobiol 16: 263-303.

McAlonan K, Brown VJ. 2003. Orbital prefrontal cortex mediates reversal learning and not attentional set shifting in the rat. Behav Brain Res 146: 97-103.

Monda M, Viggiano A, Viggiano A, Fuccio F, De L, V. 2004. Cortical spreading depression blocks the hyperthermic reaction induced by orexin a. Neuroscience 123: 567-574.

Morin X, Cremer H, Hirsch MR, Kapur RP, Goridis $C$, et al. 1997. Defects in sensory and autonomic ganglia and absence of locus coeruleus in mice deficient for the homeobox gene Phox2a. Neuron 18: 411-423.

Mostofsky SH, Cooper KL, Kates WR, Denckla MB, Kaufmann WE. 2002. Smaller prefrontal and premotor volumes in boys with attention-deficit/ hyperactivity disorder. Biol Psychiatry 52: 785-794.

Mulder AB, Nordquist RE, Orgut O, Pennartz CM. 2003. Learning-related changes in response patterns of prefrontal neurons during instrumental conditioning. Behav Brain Res 146: 77-88.

Murugaiah KD, O'Donnell JM. 1995. Beta adrenergic receptors facilitate norepinephrine release from rat hypothalamic and hippocampal slices. Res Commun Mol Pathol Pharmacol 90: 179-190.

Naga Prasad SV, Nienaber J, Rockman HA. 2001. Beta-adrenergic axis and heart disease. Trends Genet 17: S44-S49.

Newman DB, Hilleary SK, Ginsberg CY. 1989. Nuclear terminations of corticoreticular fiber systems in rats. Brain Behav Evol 34: 223-264.

O'Donnell JM. 1993. Effect of the beta-2 adrenergic agonist zinterol on norepinephrine turnover. Res Commun Chem Pathol Pharmacol 80: 113-116.

Olpe HR, Berecek K, Jones RS, Steinmann MW, Sonnenburg C, Hofbauer KG. 1985. Reduced activity of locus coeruleus neurons in hypertensive rats. Neurosci Lett 61: 25-29.

Oostendorp J, Preitner F, Moffatt J, Jimenez M, Giacobino JP, Molenaar P, et al.. 2000. Contribution of beta-adrenoceptor subtypes to relaxation of colon and oesophagus and pacemaker activity of ureter in wildtype and beta(3)-adrenoceptor knockout mice. Br J Pharmacol 130: 747-758.

Phillipson OT. 1979. Afferent projections to the ventral tegmental area of Tsai and interfascicular nucleus: a horseradish peroxidase study in the rat. 
J Comp Neurol 187: 117-143.

Pueyo R, Maneru C, Vendrell P, Mataro M, EstevezGonzalez A, Garcia-Sanchez C, et al. 2000. [Attention deficit hyperactivity disorder. Cerebral asymmetry observed on magnetic resonance]. Rev Neurol 30: 920-925.

Raskin LA, Shaywitz BA, Anderson GM, Cohen DJ, Teicher MH, Linakis J. 1983. Differential effects of selective dopamine, norepinephrine or catecholamine depletion on activity and learning in the developing rat. Pharmacol Biochem Behav 19: 743-749.

Reith ME, Li MY, Yan QS. 1997. Extracellular dopamine, norepinephrine, and serotonin in the ventral tegmental area and nucleus accumbens of freely moving rats during intracerebral dialysis following systemic administration of cocaine and other uptake blockers. Psychopharmacology (Berl) 134: 309-317.

Reja V, Goodchild AK, Phillips JK, Pilowsky PM. 2002. Tyrosine hydroxylase gene expression in ventrolateral medulla oblongata of WKY and SHR: a quantitative real-time polymerase chain reaction study. Auton Neurosci 98: 79-84.

Robbins TW. 1997. Arousal systems and attentional processes. Biol Psychol 45: 57-71.

Rubia K, Overmeyer S, Taylor E, Brammer M, Williams SC, Simmons A, et al. 2000. Functional frontalisation with age: mapping neurodevelopmental trajectories with fMRI. Neurosci Biobehav Rev 24: 13-19.

Russell V, Allie S, Wiggins T. 2000. Increased noradrenergic activity in prefrontal cortex slices of an animal model for attention-deficit hyperactivity disorder-the spontaneously hypertensive rat. Behav Brain Res 117: 69-74.

Sadile AG. 1996. Long-term habituation of thetarelated activity components of albino rats in the Làt-maze. In: Sanberg PR, Ossenkopp KP, Kavaliers M, eds, Motor Activity and Movement Disorders: Measurement and Analysis. New York, NY, USA: Humana Press; 1-54.

Sallinen J, Haapalinna A, MacDonald E, Viitamaa T, Lahdesmaki J, Rybnikova E, et al. 1999. Genetic alteration of the alpha2-adrenoceptor subtype $c$ in mice affects the development of behavioral despair and stress-induced increases in plasma corticosterone levels. Mol Psychiatry 4: 443-452.

Schramm NL, McDonald MP, Limbird LE. 2001. The alpha(2a)-adrenergic receptor plays a protective role in mouse behavioral models of depression and anxiety. J Neurosci 21: 4875-4882.

Sergeant JA, Geurts H, Huijbregts S, Scheres A, Oosterlaan J. 2003. The top and the bottom of ADHD: a neuropsychological perspective. Neurosci Biobehav Rev 27: 583-592.

Shi WX, Pun CL, Zhang XX, Jones MD, Bunney BS. 2000. Dual effects of $D$-amphetamine on dopamine neurons mediated by dopamine and nondopamine receptors. J Neurosci 20: 3504-3511.

Spencer T, Biederman J, Wilens T, Prince J, Hatch M, Jones J, et al. 1998. Effectiveness and tolerability of tomoxetine in adults with attention deficit hyperactivity disorder. Am J Psychiatry 155: 693-695.

Spreng M, Cotecchia S, Schenk F. 2001. A behavioral study of Alpha-1B adrenergic receptor knockout mice: increased reaction to novelty and selectively reduced learning capacities. Neurobiol Learn Mem 75: 214-229.

Swanson LW. 1982. The projections of the ventral tegmental area and adjacent regions: a combined fluorescent retrograde tracer and immunofluorescence study in the rat. Brain Res Bull 9: 321-353.

Szot P, Weinshenker D, White SS, Robbins CA, Rust NC, Schwartzkroin PA, et al. 1999. Norepinephrine-deficient mice have increased susceptibility to seizure-inducing stimuli. J Neurosci 19: 10985-10992.

Takahashi N, Miner LL, Sora I, Ujike H, Revay RS, Kostic V, et al. 1997. VMAT2 knockout mice: heterozygotes display reduced amphetamineconditioned reward, enhanced amphetamine locomotion, and enhanced MPTP toxicity. Proc Natl Acad Sci USA 94: 9938-9943.

Tanaka J, Miyakubo H, Hayashi Y. 2002. Decreased monoamine release in the median preoptic area following ventricular treatment with the angiotensin II antagonist saralasin in normotensive and spontaneously hypertensive rats. Regul Pept 107: 71-77.

Tanoue A, Koshimizu TA, Tsujimoto G. 2002. Transgenic studies of alpha(1)-adrenergic receptor subtype function. Life Sci 71: 2207-2215.

Thomas DN, Holman RB. 1991. A microdialysis study of the regulation of endogenous noradrenaline release in the rat hippocampus. J Neurochem 56: 1741-1746.

Thomas SA, Marck BT, Palmiter RD, Matsumoto AM. 1998. Restoration of norepinephrine and reversal of phenotypes in mice lacking dopamine 
beta-hydroxylase. J Neurochem 70: 2468-2476.

Thomas SA, Palmiter RD. 1997. Disruption of the dopamine beta-hydroxylase gene in mice suggests roles for norepinephrine in motor function, learning, and memory. Behav Neurosci 111: 579-589.

Torrealba F, Yanagisawa M, Saper CB. 2003. Colocalization of orexin a and glutamate immunoreactivity in axon terminals in the tuberomammillary nucleus in rats. Neuroscience 119: 1033-1044.

Uylings HB, Groenewegen HJ, Kolb B. 2003. Do rats have a prefrontal cortex? Behav Brain Res 146: 3-17.

Vafaei AA, Rashidy-Pour A. 2004. Reversible lesion of the rat's orbitofrontal cortex interferes with hippocampus-dependent spatial memory. Behav Brain Res 149: 61-68.

Vanderschuren LJ, Wardeh G, De Vries TJ, Mulder AH, Schoffelmeer AN. 1999. Opposing role of dopamine D1 and D2 receptors in modulation of rat nucleus accumbens noradrenaline release. $\mathrm{J}$ Neurosci 19: 4123-4131.

Viggiano D, Grammatikopoulos G, Sadile AG. 2002. A morphometric evidence for a hyperfunctioning mesolimbic system in an animal model of ADHD. Behav Brain Res 130: 181-189.

Viggiano D, Ruocco LA, Pignatelli M, Grammatikopoulos G, Sadile AG. 2003. Prenatal elevation of endocannabinois corrects the unbalance between dopamine systems and reduces activity in the Naples High Excitability rats. Neurosci Biobehav Rev 27: 129-139.

Viggiano D, Sadile AG. 2000. Hypertrophic A10 dopamine neurons in a rat model of Attentiondeficit Hyperactivity Disorder (ADHD). Neuroreport 11: 3677-3680.

Viggiano D, Vallone D, Ruocco LA, Sadile AG. 2003. Behavioural, pharmacological, morpho-functional molecular studies reveal a hyperfunctioning mesocortical dopamine system in an animal model of attention deficit and hyperactivity disorder. Neurosci Biobehav Rev 27: 683-689.

Viggiano D, Vallone D, Sadile AG. 2004. Dysfunctions in the dopamine systems and ADHD: evidences from animals and modeling. Neural Plast 11:93-116.

Viggiano D, Vallone D, Welzl H, Sadile AG. 2002. The Naples high- and low excitability rats: selective breeding, behavioral profile, morphometry and molecular biology of the mesocortical dopamine system. Behav Genet 32: 315-333.

Weinshenker D, Miller NS, Blizinsky K, Laughlin ML, Palmiter RD. 2002. Mice with chronic norepinephrine deficiency resemble amphetamine-sensitized animals. Proc Natl Acad Sci USA 99: 13873-13877.

Williams J, Taylor E. 2004. Dopamine appetite and cognitive impairment in Attention Deficit/Hyperactivity Disorder. Neural Plast 2004. 11: 117-134.

Wong EH, Sonders MS, Amara SG, Tinholt PM, Piercey MF, Hoffmann WP, et al. 2000. Reboxetine: a pharmacologically potent, selective, and specific norepinephrine reuptake inhibitor. Biol Psychiatry 47: 81 8-829.

Xu F, Gainetdinov RR, Wetsel WC, Jones SR, Bohn LM, Miller GW, et al. 2000. Mice lacking the norepinephrine transporter are supersensitive to psychostimulants. Nat Neurosci 3: 465-471.

Yavich L, Lappalainen R, Sirvio J, Haapalinna A, MacDonald E. 1997. Alpha2-adrenergic control of dopamine overflow and metabolism in mouse striatum. Eur J Pharmacol 339: 113-1 19.

Zhou QY, Palmiter RD. 1995. Dopamine-deficient mice are severely hypoactive, adipsic, and aphagic. Cell 83: 1197-1209.

Zhou QY, Quaife CJ, Palmiter RD. 1995. Targeted disruption of the tyrosine hydroxylase gene reveals that catecholamines are required for mouse fetal development. Nature 374: 640-643.

Zuscik MJ, Sands S, Ross SA, Waugh DJ, Gaivin RJ, Morilak D, et al. 2000. Overexpression of the alpha1B-adrenergic receptor causes apoptotic neurodegeneration: multiple system atrophy. Nat Med 6: 1388-1394.

Zwart R, Verhaagh S, Buitelaar M, Popp-Snijders C, Barlow DP. 2001. Impaired activity of the extraneuronal monoamine transporter system known as uptake-2 in Orct3/Slc22a3-deficient mice. Mol Cell Biol 21: 4188-4196. 

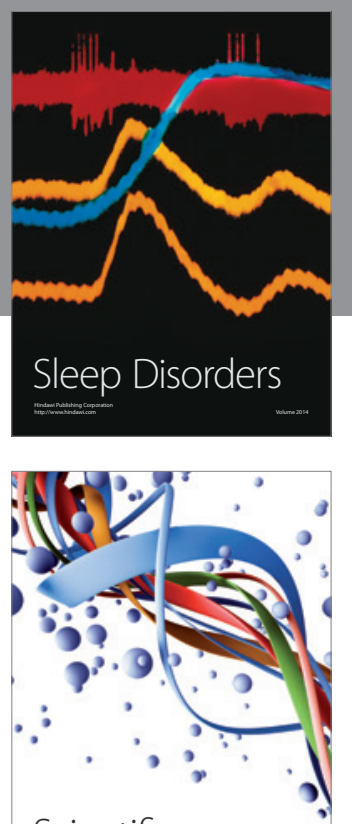

Scientifica
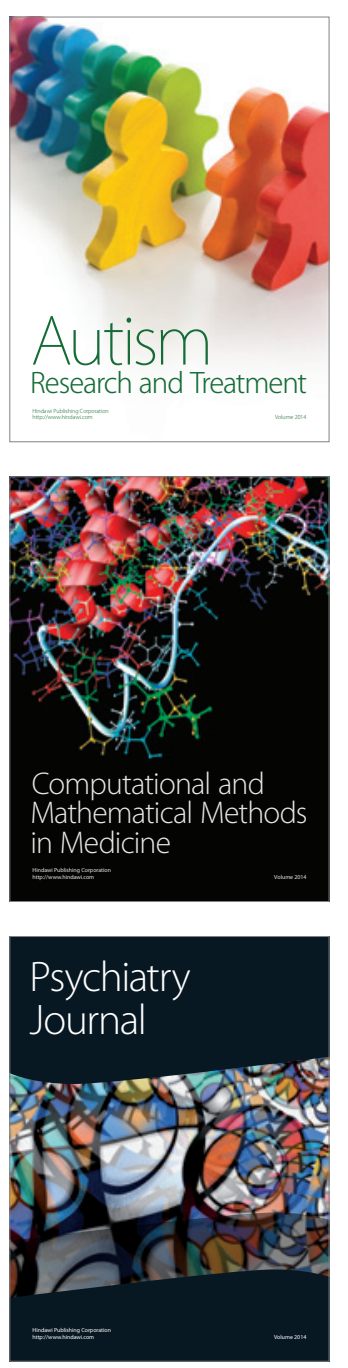
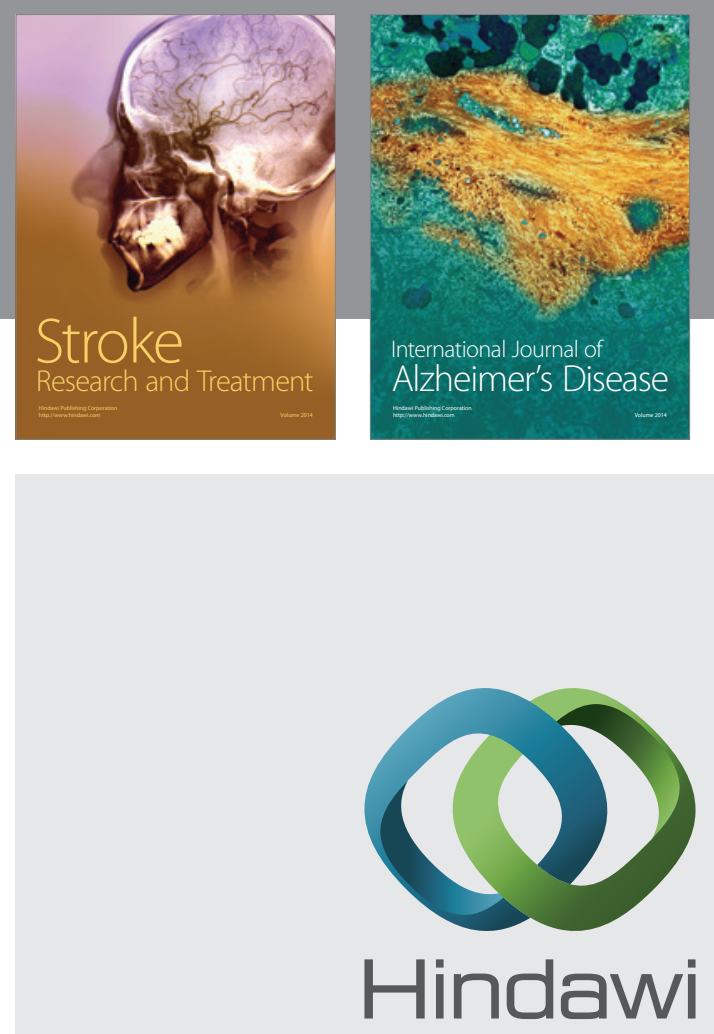

Submit your manuscripts at

http://www.hindawi.com
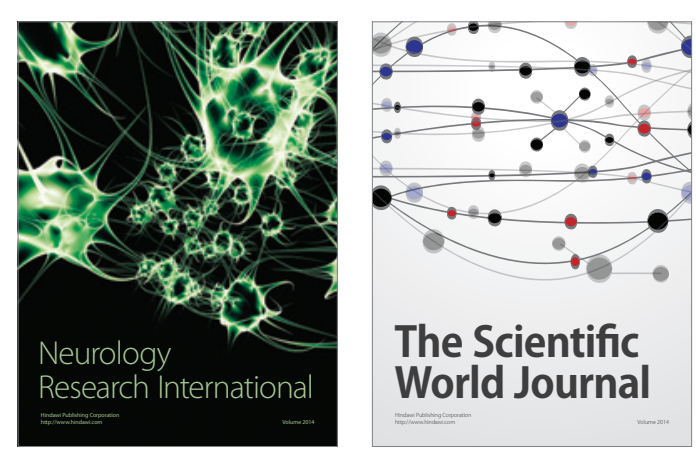

The Scientific World Journal

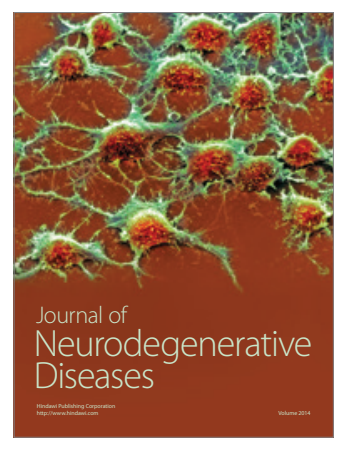

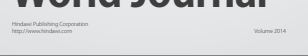

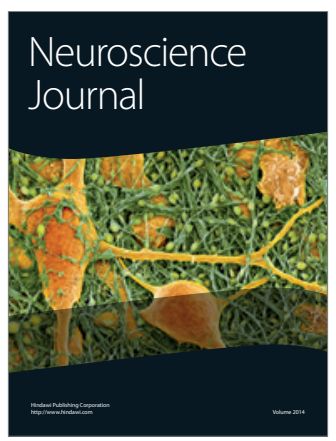

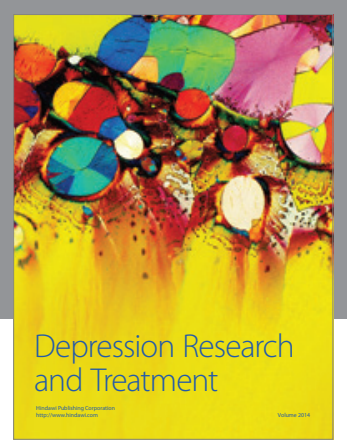
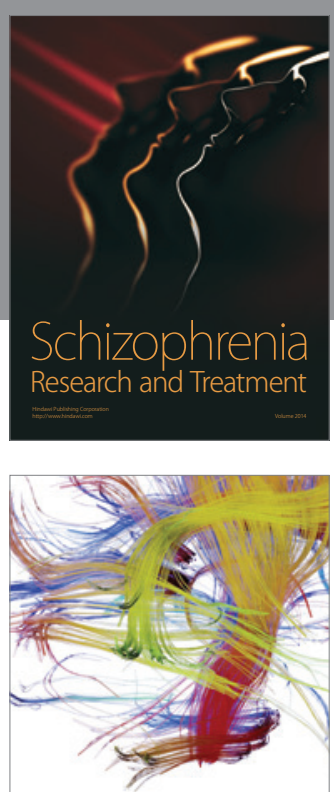

Brain Science

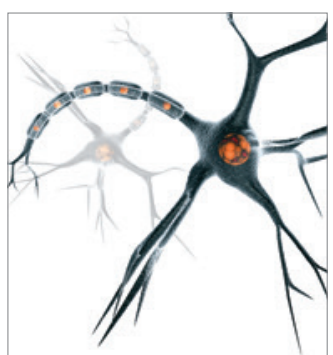

Neural Plasticity
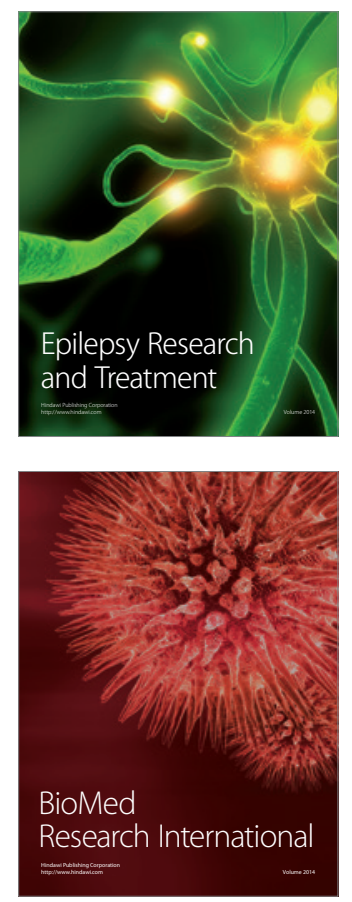

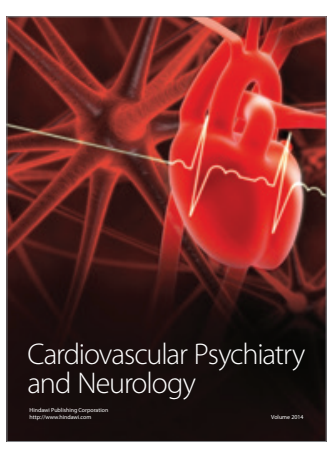

Parkinson's

Disease
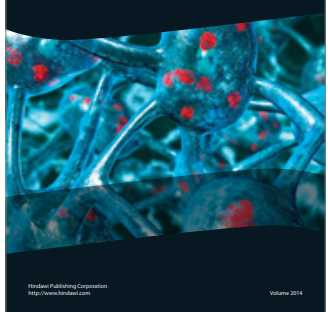